Volume 2, Nomor 1, February 2020, p. $01-04$

ISSN 2655-9951 (print), ISSN 2656-0062 (online)

\title{
Diabetes Mellitus Pada Petani
}

\author{
Refi Fandana \\ Fakultas Kedokteran Universitas Lampung \\ Email: refi.fandana21@gmail.com
}

\begin{tabular}{|c|c|}
\hline ARTICLE INFO & A B S T R A C T \\
\hline $\begin{array}{l}\text { *) corresponding author } \\
\text { Perum Arum Lstari Permai } 4 \text { Blok D2, } \\
\text { Untung Suropati, Bandar Lampung, HP } \\
082328081251\end{array}$ & $\begin{array}{l}\text { Diabetes mellitus is a chronic metabolic disease that still remains a } \\
\text { significant health problem in the world. In Indonesia, } 7 \text { percent of } \\
\text { people age }>15 \text { have diabetes, and it caused } 99.400 \text { deaths in } 2014 \text {. } \\
\text { There are typical symptoms such as polyuria, polyphagia, polydipsia, } \\
\text { and weight loss, and other symptoms. Diabetes mellitus is a } \\
\text { multifactorial disease that affected by genetic component, environment, } \\
\text { social, and culture. One of the risk factors that effect is exposure to } \\
\text { chemical compound for example pesticides. Pesticides are chemical } \\
\text { compounds that are used to kill pests in various sectors of life. } \\
\text { Agricultural culture is related to pesticides. Pesticides are potentially } \\
\text { toxic to a human when humans are exposed to pesticides through oral, } \\
\text { transdermal, or inhalation. The pesticides that enter the human } \\
\text { digestive system will be converted into glucose by gluconeogenesis in } \\
\text { the intestine and liver. Moreover, there is a relationship between work } \\
\text { period, pesticide spraying frequency, use of personal protective } \\
\text { equipment, and pesticide dosage with the incidence of diabetes mellitus } \\
\text { type 2. Farmers are a higher risk of diabetes mellitus type } 2 \text {. }\end{array}$ \\
\hline
\end{tabular}

This is an open access article under the CC-BY-SA license.

\section{PENDAHULUAN}

Diabetes melitus (DM) masih menjadi masalah kesehatan di dunia dengan jumlah penderita pada usia dewasa mengalami kenaikan setiap tahunnya dan menjadi 422 juta orang pada tahun 2014 . Diabetes melitus diperkirakan menyerang satu diatara sebelas orang di dunia (WHO, 2017). Pada tahun 2016 DM merupakan penyebab kematian nomor tujuh di dunia dengan jumlah kematian 1,6 juta (WHO, 2018).

Survei yang dilakukan riskesdas tahun 2013 didapatkan bahwa diabetes melitus menyerang 7\% populasi Indonesia dan menyebabkan 99.400 kematian. Menurut pekerjaan, petani menempati 
urutan ketiga penderita diabetes di Indonesia dengan angka 6,2\%. Diabetes melitus juga dikenal sebagai silent killer karena penyakit ini sering tidak disadari oleh penderitanya dan diketahui saat sudah tejadi komplikasi (Kemenkes RI, 2014)..

Komplikasi yang disebabkan oleh diabetes melitus terbagi menjadi komplikasi mikropati dan makropati. Stroke, kebutaan, gagal jantung, gagal ginjal, dan amputasi merupakan komplikasi yang paling banyak ditemukan (WHO, 2017; ADA, 2018; PERKENI, 2015).

Petani merupakan kelompok orang yang berisiko terkena diabetes melitus. Hal ini terjadi diduga karena paparan pestisida. Penelitian yang telah dilakukan menunjukkan hubungan antara penggunaan pestisida dengan kejadian diabetes mellitus (Evangelou, 2016; Juntarawijit, 2018; Velmurugan, 2017; Saputri, 2018).

\section{METODE}

Suatu tinjauan literatur (literature review) terhadap teori-teori yang berhubungan. Sumber literature meliputi studi pencarian database (NCBI, Google scholar, WHO, PERKENI dll) yang didapatkan total dari 13 jurnal.

\section{HASIL DAN PEMBAHASAN}

Diabetes melitus (DM) merupakan penyakit metabolik kronis dengan karakteristik hiperglikemia, hal ini dapat terjadi akibat adanya gangguan sekresi insulin, kerja insulin atau keduanya. Gangguan insulin yang berlangsung secara terus menerus ini akan mengakibatkan resistensi insulin. Pada keadaan normal tubuh dapat mengatasi resistensi insulin dengan meningkatkan sekresi insulin dan mencegah hiperglikemi, tetapi jika sudah terdapat gabungan antara defek sekresi insulin dengan resistensi insulin maka akan terjadilah hiperglikemi (PERKENI, 2015; Permentan, 2015). DM tipe 2 terjadi akibat tubuh tidak dapat menggunakan insulin yang diproduksi dengan baik, dan DM gestasional yaitu DM yang terjadi sementara pada saat kehamilan (WHO, 2017; PERKENI, 2015; Permentan, 2015). .

Diabetes melitus juga berhubungan erat dengan gaya hidup termasuk kurangnya aktivitas fisik, merokok, konsumsi alkohol, pola tidur dan status kehamilan. Penelitian terbaru menujukkan bahwa kontaminasi lingkungan oleh bahan kimia menjadi salah satu faktor risiko. Bahan kimia yang diduga meningkatkan risiko diabetes melitus adalah arsen, merkuri, phthalates, bisphenol A (BPA) dan pestisida (Juntarawijit, 2018).

Pestisida berasal dari kata pest yang berarti hama dan sida dari kata caedo yang berarti pembunuh. Pestisida dapat diartikan sebagai bahan kimia yang digunakan untuk membunuh hama termasuk serangga, hewan pengerat, jamur dan tanaman liar (WHO, 2018).

Dari penelitian Eunike Galuh dkk pada tahun 2018 terjadinya diabetes mellitus tipe 2 pada petani dihubungkan dengan masa kerja petani penyemprot di kecamatan Ngablak Kabupaten Magelang.

Tabel 1

Hubungan masa kerja dengan kejadian Diabetes Melitus tipe 2

\begin{tabular}{l|cc|cc}
\hline \multicolumn{1}{c|}{ Masa Kerja } & Kasus (F) & \% & Kontrol (F) & \% \\
\hline$<20$ tahun & 2 & 3,125 & 16 & 25 \\
$\geq 20$ tahun & 30 & 46,875 & 16 & 25 \\
Jumlah & 32 & 50,0 & 31 & 50,0 \\
\hline
\end{tabular}


Dari hasil penelitian terbaru menunjukkan bahwa $\mathrm{p}_{\text {value }}$ sebesar $0,00<0,05$ dengan nilai OR sebesar 15 dengan CI 95\% 3,06 - 73,58 yang menunjukkan bahwa petani dengan masa kerja $>20$ tahun memiliki risiko 15 kali lebih besar untuk menderita penyakit diabetes mellitus tipe 2 (Saputri, E. G., \& al., e, 2018). Pestisida memiliki efek toksik apabila manusia terpapar baik melalui rute oral, perkutan atau inhalasi. Pestisida yang mauk melalui rute oral akan masuk ke dalam sistem pencernaan dan dimetabolisme menjadi asam asetat oleh mikroba usus. Selain hal itu terdapat pula hubungan terjadinya diabetes melitus tipe 2 dengan frekuensi penyemprotan.

Tabel 2

Hubungan frekuensi penyemprotan dengan kejadian Diabetes Melitus tipe 2

\begin{tabular}{l|cc|cc}
\hline \multicolumn{1}{c|}{ Frekuensi Penyemprotan } & Kasus $(\mathbf{F})$ & $\boldsymbol{\%}$ & Kontrol (F) & \% \\
\hline$<2$ kali/minggu & 26 & 40,6 & 16 & 25 \\
$\geq 2$ kali/minggu & 6 & 9,4 & 16 & 25 \\
Jumlah & 32 & 50 & 32 & 50 \\
\hline
\end{tabular}

Pada hasil uji statistik menunjukkan $\mathrm{p}_{\text {value }}$ sebesar $0,008<0,05$ nilai $\mathrm{OR}=0,23$ dengan CI $95 \%$ 0,07 - 0,71 sehingga dapat disimpulkan bahwa frekuensi penyemprotan memiliki hubungan yang signifikan dengan kejadian diabetes mellitus tipe 2, dan merupakan faktor protektif dikarenakan nilai OR $0,23<1$. Pestisida yang disemprotkan akan mencemari lingkungan karena terjadi penimbunan residu pestisida dalam tanah. Semakin sering pestisida tersebut diaplikasikan maka proses berkembangnya resistensi akan semakin cepat, serta semakin banyak pestisida yang masuk dalam tubuh (Saputri, E. G., \& al., e, 2018).

Asam asetat yang dihasilkan akan diserap oleh sel-sel usus dan ditranspor ke hati melalui vena periportal. Asam asetat yang diserap selanjutnya akan diubah melalui proses glukoneogenesis menjadi glukosa. Paparan pestisida yang terjadi terus menerus menyebabkan jumlah glukosa dalam darah melebihi batas normal dan berakibat pada terjadinya penyakit diabetes melitus (Velmurugan, 2017).

Petani merupakan kelompok orang dengan risiko tinggi mengalami DM karena mereka sering menggunakan pestisida dalam pekerjaannya. Beberapa penelitian yang sudah pernah dilakukan menunjukkan bahwa organochloride (OC) merupakan faktor risiko terjadinya diabetes melitus tipe 2 pada petani diseluruh dunia (Evangelou, 2016).

Selain OC, penelitian di Thailand menunjukkan diabetes melitus pada petani dipengaruhi oleh semua jenis pestisida meliputi insektisida, herbisida, fungisida, rodentisida, moluskisida (Juntarawijit, 2018). Periode kerja, frekuensi penyemprotan pestisida, penggunaan alat pelindung diri (APD) saat menyemprot dan dosis pestisida mempunyai hubungan yang signifikan terhadap tejadinya DM tipe 2 pada petani penyemprot di Magelang (Saputri,2018).

Diabetes melitus merupakan penyakit metabolik kronis yang masih menjadi masalah kesehatan. Penelitian terbaru menunjukkan bahwa pencemaran lingkungan oleh bahan kimia seperti pestisida meningkatkan risiko diabetes berhubungan dengan masa kerja dan frekuensi penyemprotan.

Pestisida yang tertelan dan masuk kedalam sistem pencernaan akan diubah oleh mirkoba usus menjadi asam asetat yang kemudian akan diubah menjadi glukosa melalui glokoneogenesis di usus dan hati. Peningkatan kadar glukosa yang terjadi terus menerus akan menyebabkan terjadinya diabetes melitus. 


\section{SIMPULAN DAN SARAN}

Risiko terjadinya diabetes melitus pada petani menjadi lebih besar karena pada petani penggunaan pestisida bisa meningkatkan kadar glukosa dalam darah.

\section{DAFTAR PUSTAKA}

Ameriana, M. (2008). Perilaku Petani Sayuran dalam Menggunakan Pestisida Kimia. J. Hort., $1(18), 95-106$.

American Diabetes Association. (2018). Diabetes Care: Standars of Medical Care in Diabetes 2018. USA: American Diabetes Association.

CDC. (2017, Juli 25). Diabetes Home: Who's at Risk? Diambil kembali dari Center for Disease Control and Prevention: https://www.cdc.gov/diabetes/basics/risk-factors.html

Evangelou, E., \& al., e. (2016, Februari 8). Exposure to Pesticide and Diabetes: A Systematic Review and Meta-alysis. Environtment International, 91, 60-68.

Juntarawijit, C., \& Juntarawijit, Y. (2018, Januari 27). Association Between Diabetes and Pesticides: A Case-control Study Among Thai Farmers. Environmental Health and Preventive Medicine, 3(23), 1-10.

Kemenkes RI. (2014). Infodatin: Situasi dan Analisis Diabetes. Jakarta: Kementrian Kesehatan RI.

Peraturan Menteri Pertanian Republik Indonesia Nomor 39/Permentan/SR.330/7/2015 tentang Pendaftaran Pestisida

PERKENI. (2015). Konsensus Pengelolaan dan Pencegahan Diabetes Melitus Tipe 2 Di Indonesia. Jakarta: PB Perkeni.

Saputri, E. G., \& al., e. (2018, Januari 1). Hubungan RIwayat Pajanan Pestisida dengan Kejadian Diabetes Melitus Tipe 2 pada Petani Penyemprot di Kecamatan Ngablak Kabupaten Magelang. Jurnal Kesehatan Masyarakat e-Journal, 6(1), 645-654.

Velmurugan G, e. a. (2017, Januari 27). Gut Microbial Degradation of Organophosphate Insecticides-induces Glucose Intolerance via Gluconeogenesis. Genome Biology, 8(18), 118.

WHO. (2017, November 15). Key fact: Diabetes. Diambil kembali dari World Health Organization: http://www.who.int/news-room/fact-sheets/detail/diabetes

WHO. (2018, Februari 19). Pesticide residues in food. Dipetik Oktober 23, 2018, dari World Health Organization: http://www.who.int/en/news-room/fact-sheets/detail/pesticide-residues-infood

WHO. (2018, Mei 24). The top 10 causes of death. Dipetik Oktober 23, 2018, dari World Health Organization: http://www.who.int/news-room/fact-sheets/detail/the-top-10-causes-of-death 